\title{
Knowledge in numbers
}

\author{
Paul Kurlansky, $\mathrm{MD},{ }^{\mathrm{a}}$ and Emilia Bagiella, $\mathrm{PhD}^{\mathrm{b}}$
}

From the ${ }^{\mathrm{a} D e p a r t m e n t}$ of Surgery, Columbia University, New York; and ${ }^{\mathrm{b}}$ Department of Population Health Science and Policy, Icahn School of Medicine at Mount Sinai, New York, NY.

Received for publication June 13, 2019; revisions received June 26, 2019; accepted for publication July 4, 2019; available ahead of print Nov 6, 2019.

Address for reprints: Paul Kurlansky, MD, Columbia University Medical Center, Black Building 210, 650 West 168th St, New York, NY 10032 (E-mail: pk2245@cumc.columbia.edu).

J Thorac Cardiovasc Surg 2020;159:1258-9

0022-5223/\$36.00

Copyright (C) 2019 Published by Elsevier Inc. on behalf of The American Association for Thoracic Surgery

https://doi.org/10.1016/j.jtcvs.2019.07.148

\section{"A good decision is based on knowledge and not on numbers."}

$$
\text { -Plato }
$$

Since the New England Journal of Medicine (NEJM) publication of the now-classic works of Luft and colleagues ${ }^{1}$ and of Birkmeyer and colleagues ${ }^{2}$ detailing the relationship between volume and mortality for complex surgical procedures, procedural volume has become the darling metric for the quality gurus. With the dissemination of transcatheter aortic valve replacement, this relationship has assumed a role of central importance, as volume requirements are imbedded in the Centers for Medicare \& Medicaid Services coverage plans for reimbursement. It is therefore both appropriate and welcome to find the careful analysis of the comprehensive data from the Transcatheter Valve Registry recently reported in the NEJM. ${ }^{3}$ The data encompass all centers approved for the procedure by Centers for Medicare \& Medicaid Services for the years 2015 to 2017 and involved appropriately sophisticated statistical methodology that adjusted for important covariates and accounted for the potentially nested relationship at the level of hospital, operator, and patient. Even when accounting for associated risk factors, there appeared to be a clear relationship between volume and mortality (although this relationship was less apparent for procedural complications). Presumably for analytical clarity, authors then segregated the data into quartiles, demonstrating a graded relationship, with the greatest-volume centers and operators having the lowest risk-adjusted mortality. The implications of the data seem clear. Leaving aside thorny and complex issues of patient access, in the ideal world, patients should be treated by the greatestvolume operators at the greatest-volumes centers. Or should they?

More nuanced examination of the data reveals that despite the satisfaction of $P$ values driven by sample size, the actual effect size between the greatest- and portion B).

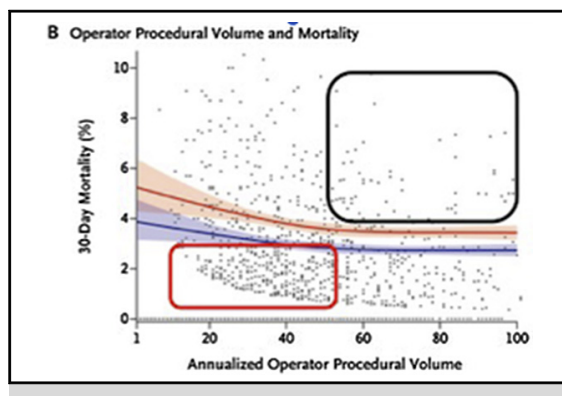

Volume mortality relationship by center and operator.

Central Message

Although there is correlation between procedural volume and mortality for TAVR, the relationship is complex and should not replace careful evaluation of professionally driven metrics of quality.

This Invited Expert Opinion provides a perspective on the following paper: $N$ Engl $J$ Med. 2019;380:2541-2550. https://doi.org/10. 1056/NEJMsa1901109.

See Commentary on page 1260 .

lowest-volume centers was only $0.5 \%$ (risk adjusted mortality $3.19 \%$ vs $2.66 \%$ ), which would translate into a number needed to treat of 200 . That said, if that one mortality is yours or that of your loved one, the difference remains compelling. However, even though the authors chose to divide their data into quartiles, the results of their analysis seemed to follow a much more bimodal distribution, with volume transition among the hospitals somewhere in the range of 125 transcatheter aortic valve replacement procedures, and, for the operators somewhere in the range of 50, both of which would fall within the top quartile (see portions C and D of Figure 1, which is adapted from Figure 2 of the NEJM article). If we were indeed to apply these criteria, we would eliminate the many centers and operators whose risk-adjusted results are better than expected (red rectangles in portions $\mathrm{A}$ and $\mathrm{B}$ of Figure 1), and, perhaps even more disturbing, empower a certain number of operators whose results are notably worse than expected (black rectangle in

Although volume has a definitive appeal as a metric of quality—easy to measure, easy to document-it is no 


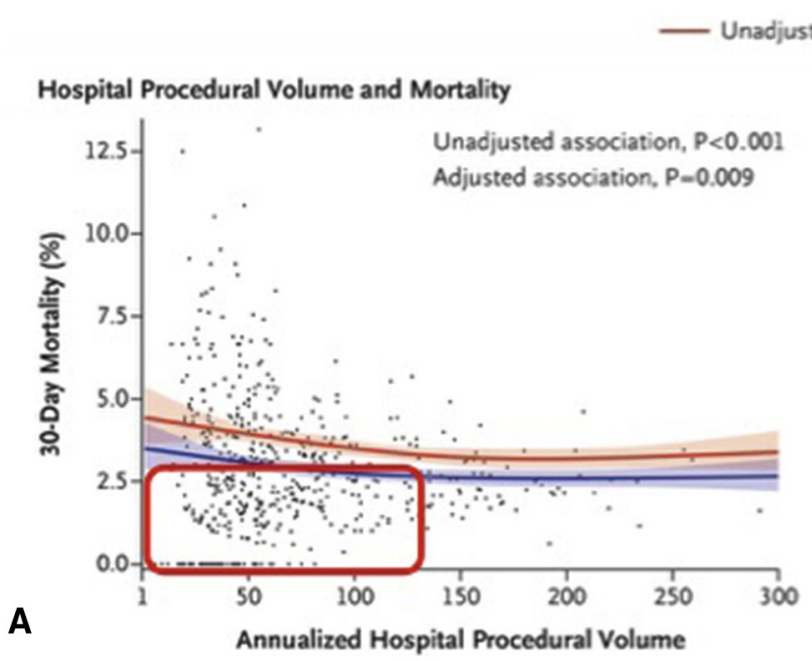

B

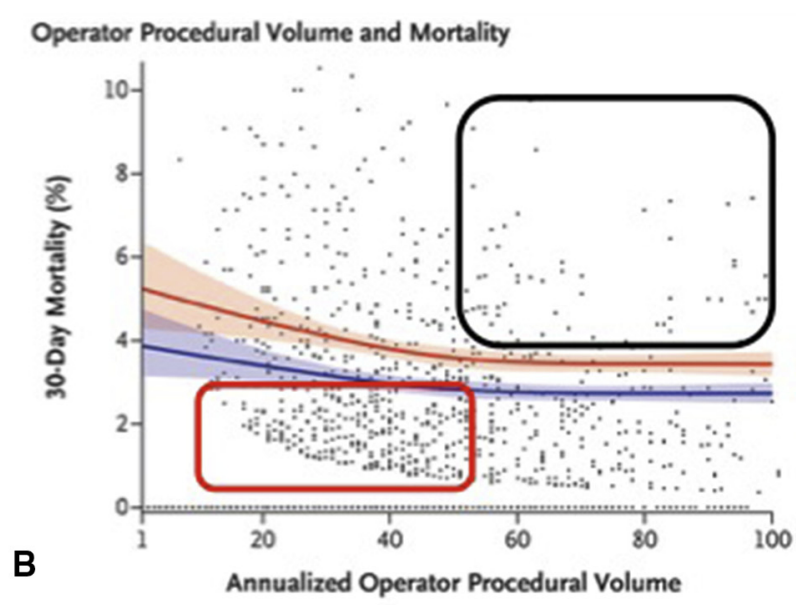

Mortality with Respect to Hospital Procedural Volume

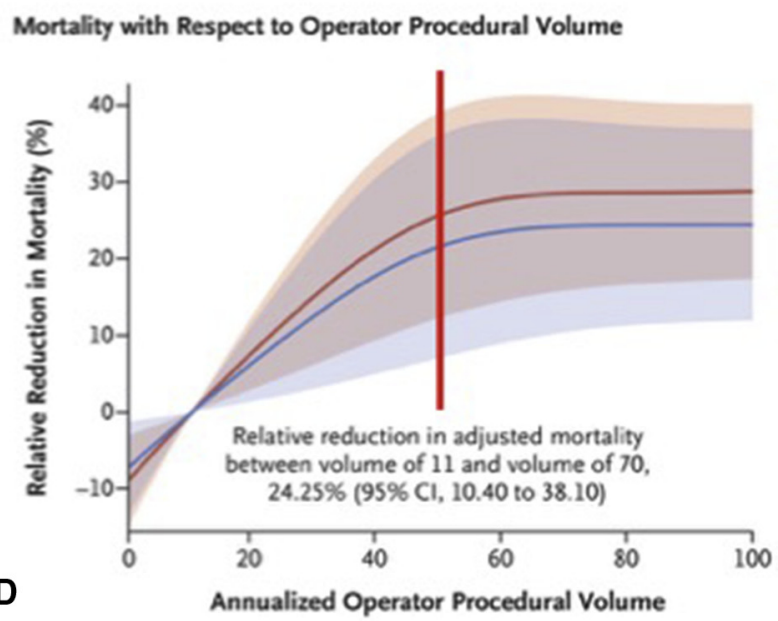

C

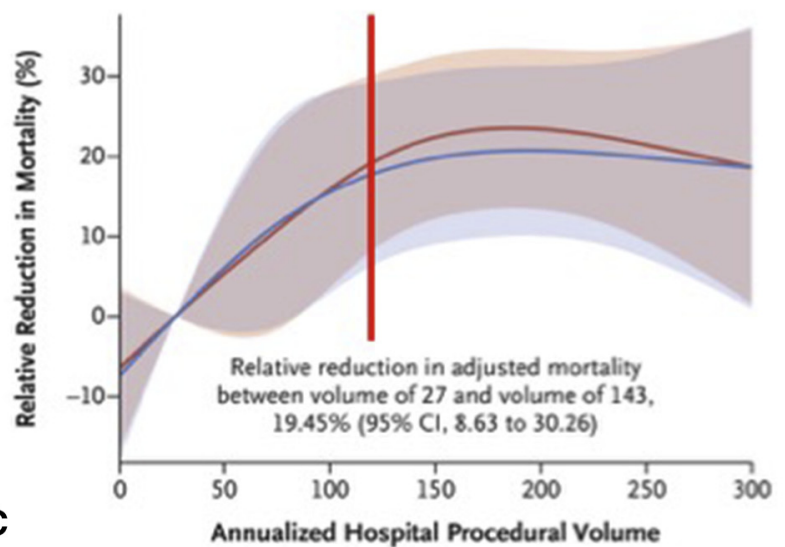

FIGURE 1. Adopted from Figure 2 of Vemulapalli and colleagues. ${ }^{3}$ Relationship between procedural volume and mortality. A and B demonstrate relationship between transcatheter aortic valve replacement volume and mortality for hospitals (A) and operators (B) (black dots represent individual hospitals/operators). $\mathrm{C}$ and $\mathrm{D}$ estimate the relative reduction in mortality at given levels of TAVR volume for hospitals (C) and operators (D). Red vertical lines in C and D represent volume thresholds at which no further volume benefit is observed. Red boxes in A and B represent hospitals (A) and operators (B) who had lower volume than the thresholds in C and D, yet had lower than expected mortality. Black box in B highlights operators whose volume exceeded the threshold in D but whose mortality was greater than expected.

replacement for the careful, painstaking, and frequently complex effort needed to develop and apply clinically meaningful metrics of quality. ${ }^{4}$ Although volume clearly has a role, the relationship is not necessarily simple and should not displace professionally validated metrics such as have been developed by the Society of Thoracic Surgeons for the most common operations in cardiac surgery and are in evolution through the collaboration of the Society of Thoracic Surgeons and the American College of Cardiology from the data in the Transcatheter Valve Therapy Registry. These carefully crafted metrics will ultimately be the most reliable and effective instruments to help drive physician decision-making and sustainable clinical quality improvement.

\section{Conflict of Interest Statement}

Authors have nothing to disclose with regard to commercial support.

\section{References}

1. Luft HS, Bunker JP, Enthoven AC. Should operations be regionalized? The empirical relation between surgical volume and mortality. N Engl J Med. 1979;301:1364-9.

2. Birkmeyer JD, Siewers AE, Finlayso EVA, Stukel TA, Luas FL, Batista I, et al. Hospital volume and surgical mortality in the United States. $N$ Engl J Med. 2002;346:1128-37.

3. Vemulapalli S, Carroll JD, Mack MJ, Li Z, Dai D, Kosinski AS, et al. Procedural volume and outcomes for transcatheter aortic-valve replacement. $N$ Engl J Med. 2019;380:2541-50.

4. Kurlansky PA, Argenziano M, Dunton R, Lancey R, Nast E, Stewart A, et al. Quality not volume, determines outcome of coronary artery bypass surgery in a universitybased community hospital network. J Thorac Cardiovasc Surg. 2012;143:287-93. 